Int. J. Electrochem. Sci., 14 (2019) $11692-11705$

International Journal of

ELECTROCHEMICAL

SCIENCE

$\underline{\text { WWW.electrochemsci.org }}$

\title{
Fabrication of Nanocrystalline Ni-Co Coatings by Electrodeposition under Supergravity Field
}

\author{
Xiaoyun $\mathrm{Hu}^{1, *}$, Ningsong $Q u^{1,2}$ \\ ${ }^{1}$ Nanjing University of Aeronautics and Astronautics, Nanjing 210016, People's Republic of China \\ 2 Jiangsu Key Laboratory of Precision and Micro-Manufacturing Technology, Nanjing 210016, \\ People's Republic of China \\ *E-mail: hxyun@ nuaa.edu.cn
}

doi: $10.20964 / 2019.12 .01$

Received: 22 March 2019 / Accepted: 16 July 2019 / Published: 29 October 2019

$\mathrm{Ni}$-Co coatings on stainless steel substrates are prepared using electrodeposition assisted by a supergravity field. Transmission electron microscopy reveals the nanometer-scale grain size of the asprepared Ni-Co coatings, confined to around $15 \mathrm{~nm}$, to have likely been due to crystal formation and growth under supergravity conditions. In comparison, electrodeposited coatings obtained under normal gravity without the addition of saccharin exhibit a much larger grain size. Energy dispersive spectroscopy analysis clearly shows a Co content of 40.56 wt.\% in the Ni-Co coatings after having used a Co bath concentration of $40 \mathrm{~g} / \mathrm{l}$, which cannot be achieved under normal gravity. A maximum microhardness of $660 \mathrm{HV}$ is obtained, also unachievable under normal gravity. Moreover, Ni-Co coatings produced under supergravity show increased resistance to wear compared with their normalgravity counterparts. We conclude that the high quality inherent to the nanocrystalline $\mathrm{Ni}-\mathrm{Co}$ coatings originates from the improved crystallinity and increased Co content arising from the use of supergravity.

Keywords: electrodeposition; Ni-Co coating; supergravity field; microhardness; wear resistance

\section{$\underline{\text { FULL TEXT }}$}

(C) 2019 The Authors. Published by ESG (www.electrochemsci.org). This article is an open access article distributed under the terms and conditions of the Creative Commons Attribution license (http://creativecommons.org/licenses/by/4.0/). 